\title{
Polymorphisms and functional activity in superoxide dismutase and catalase genes in smokers with COPD
}

\author{
J.C.W. Mak*, S.P. Ho*, W.C. Yü ${ }^{\#}$, K.L. Choo", C.M. Chu ${ }^{+}$, W.W. Yew ${ }^{\S}$, W.K. Lam and \\ M. Chan-Yeung*, , on behalf of the Hong Kong Thoracic Society Chronic \\ Obstructive Pulmonary Disease Study Group
}

ABSTRACT: Increased oxidative stress has been implicated in the pathogenesis of chronic obstructive pulmonary disease (COPD). This study investigated the risk of COPD and the substitution of alanine 16 with valine (Ala16Val) polymorphism of manganese-superoxide dismutase (Mn-SOD) and the cytosine to thymidine transition of nucleotide $-262(-262 \mathrm{C}>\mathrm{T})$ polymorphism of the catalase gene, and the activity of erythrocyte SOD and catalase.

The subjects were stable COPD patient ever smokers $(n=165)$ and healthy controls, matched for age and cigarette consumption. Genotyping of Mn-SOD at Ala16Val and the catalase gene at $-262 C>T$ was performed, and the functional activity of SOD and catalase in erythrocytes determined.

There were no significant differences in the distribution of the different genotypes or allele frequencies between patients and controls for both the Mn-SOD and catalase genes. Among healthy controls or COPD patients, no differences were observed in erythrocyte SOD and catalase activity, irrespective of genotype. Significantly higher erythrocyte catalase activity was found in COPD patients than in healthy controls. The T/T catalase genotype and Ala/Ala Mn-SOD genotype were uncommon in the present Chinese population.

The increase in erythrocyte catalase activity in Chinese patients with chronic obstructive pulmonary disease probably indicates dysfunction of the oxidant/antioxidant defence system, but it is unclear whether this increase is compensatory or a pathogenic factor.

KEYWORDS: Catalase, chronic obstructive pulmonary disease, genetic polymorphisms, manganese superoxide dismutase

igarette smoking is the most important aetiological factor for the development of chronic obstructive pulmonary disease (COPD). There is a dose-dependent relationship between the cumulative amount of smoking and the incidence of this disease [1]. Cigarette smoke contains massive amounts of oxidants, in both the gas phase and particulate matter $\left(\sim 1 \times 10^{14}\right.$ free radicals $\cdot$ puff $\left.^{-1}\right)$ [2]. It is known that cell damage induced by the superoxide radical $\left(\mathrm{O}_{2}^{--}\right)$ and related oxygen species is involved in the pathogenesis of many diseases, including COPD [3]. In humans, a complex defence antioxidative system is available to protect against the toxicity of active oxygen species [4]. It consists of antioxidant enzymes and some nonenzymatic free radical scavengers. The specific enzymes catalysing the breakdown of $\mathrm{O}_{2}^{--}$and hydrogen peroxide include superoxide dismutase (SOD), catalase and glutathione peroxidase (GPx). The main task of these enzymes is to neutralise free radicals and prevent the transformation of $\mathrm{O}_{2}^{-}$ into hydroxyl radicals [5]. The major defence against the toxicity of $\mathrm{O}_{2}^{--}$is conferred by SOD, which catalyses the dismutation of $\mathrm{O}_{2}^{--}$to $\mathrm{H}_{2} \mathrm{O}_{2}$. The SOD family is composed of three metalloenzymes, copper-zinc-SOD (SOD1), manganeseSOD (Mn-SOD; SOD2) and extracellular SOD (SOD3). Catalase, the main enzyme scavenging $\mathrm{H}_{2} \mathrm{O}_{2}$, decomposes $\mathrm{H}_{2} \mathrm{O}_{2}$ to water and therefore acts in concert with SOD. The $\mathrm{H}_{2} \mathrm{O}_{2}$ is also deactivated to water by GPx, which uses reduced glutathione (GSH) as a hydrogen donor, whereby GSH is oxidised.

In 2006, the risk of developing COPD among continuous smokers was estimated to be $\geqslant 25 \%$ [6], suggesting that there must be risk factors contributing to the susceptibility to this disease. Interindividual variation in antioxidant capacity
AFFILIATIONS

*Division of Respiratory Medicine, Dept of Medicine, Queen Mary Hospital, The University of Hong Kong,

\#Princess Margaret Hospital,

"North District Hospital and

+United Christian Hospital,

${ }^{\S}$ Grantham Hospital, Hong Kong SAR, China

${ }^{f}$ Occupational and Environmental

Lung Diseases Unit, Respiratory

Division, Dept of Medicine,

University of British Columbia,

Vancouver, BC, Canada.

CORRESPONDENCE

M. Chan-Yeung

University Dept of Medicine

4/F, Professorial Block

Queen Mary Hospital

Hong Kong SAR

China

Fax: 85228551143

E-mail: mmwchan@hkucc.hku.hk

Received:

February 072007

Accepted after revision:

May 252007

SUPPORT STATEMENT

The study was supported by a Hong Kong University Committee on

Research and Conference research

grant and the Hong Kong Lung

Foundation (both Hong Kong SAR,

China).

STATEMENT OF INTEREST

None declared.

European Respiratory Journal

Print ISSN 0903-1936

Online ISSN 1399-3003 
may exist as a result of polymorphisms of genes regulating antioxidant enzymes. Mn-SOD is encoded by a single gene, containing five exons and located on chromosome 6q25 [7]. One of the polymorphisms of Mn-SOD results in the replacement of alanine 16 (GCT) with a valine (GTT; the Ala16Val polymorphism), and affects the import of Mn-SOD into mitochondria by altering the conformation of its leader signal [8]. The Ala variant of Mn-SOD has been associated with an increased risk of lung cancer but not of COPD [9, 10].

The catalase gene contains 13 exons and is located on chromosome 11p13 [11]. Several polymorphisms in the catalase gene, characterised by erythrocyte catalase levels $0.2-4 \%$ of normal, have been reported. A point guanosine to adenine transition $(\mathrm{G}>\mathrm{A})$ mutation in intron 4 results in abnormal splicing and, in addition, a thymidine deletion in exon 4 has been reported in a case of acatalasia in Japan [12]. The common cytosine to thymidine transition of nucleotide $-262(-262 \mathrm{C}>\mathrm{T})$ polymorphism is associated with both basal catalase expression and the level of this enzyme in erythrocytes [13]. The catalase gene polymorphism $-21 \mathrm{~A}>\mathrm{T}$ has recently been reported not to be associated with the risk of developing COPD [10], but the role of the functional polymorphism $-262 \mathrm{C}>\mathrm{T}$ has not yet been studied.

Since interindividual variation in antioxidant capacity may occur as a result of functional polymorphisms of genes regulating antioxidant enzyme activity, it was hypothesised that such polymorphisms of the Mn-SOD and catalase genes might be related to the development of COPD. In the present study, the prevalence of the Ala16Val Mn-SOD and 262C>T catalase gene polymorphisms, and the functional enzyme activities of SOD and catalase, were compared in Chinese patients with COPD and healthy controls.

\section{METHODS}

\section{Subjects}

Consecutive patients $(n=165)$ with stable COPD were recruited from the outpatient clinics of five hospitals (Queen Mary Hospital (University of Hong Kong), Princess Margaret Hospital, North District Hospital, United Christian Hospital and Grantham Hospital) in Hong Kong SAR, China. The patients were current or ex-smokers and satisfied the Global Initiative for Chronic Obstructive Lung Disease (GOLD) clinical criteria for COPD [14], i.e. post-bronchodilator forced expiratory volume in one second (FEV1) $<80 \%$ of the predicted value, FEV1/forced vital capacity (FVC) $<70 \%$, and FEV1 bronchodilator response $<12 \%$ or $<200 \mathrm{~mL}$ with or without symptoms of cough, phlegm and shortness of breath on exertion. Each patient was matched for age ( $\pm 5 \mathrm{yrs})$ and cumulative cigarette consumption $( \pm 5$ pack-yrs) with a healthy subject without respiratory symptoms and normal lung function (FEV1 $\geqslant 80 \%$ pred; FEV1/FVC $\geqslant 70 \%$ ) as a control. The predicted values were based on reference values obtained from the local population [15]. The controls were recruited from the general population, as described in a previous communication [15]. Other sources were community centres and churches for the elderly in different parts of Hong Kong. In addition to lung function testing, these subjects were interviewed using a detailed questionnaire to obtain information on smoking habits, respiratory symptoms and other illnesses. Ex-smokers were defined as those who had not smoked within the previous 12 months. Patients and controls provided a $10-\mathrm{mL}$ venous blood sample. All subjects were ethnically Chinese and originated from Hong Kong or the Guangdong province of Southern China. The Ethics Committee of the University of Hong Kong approved the study protocol and all of the participants provided written informed consent.

\section{Blood collection and storage}

Smoking patients and controls were told to refrain from smoking for $\geqslant 12 \mathrm{~h}$ before blood was taken. Whole blood was collected from each subject in lithium heparin and centrifuged for $10 \mathrm{~min}$ at $1,600 \times g$. Red blood cells were separated and stored at $-70^{\circ} \mathrm{C}$ until biochemical measurements were performed. Red blood cell lysates were prepared by washing packed red blood cells three times with cold normal saline via centrifugation for $10 \mathrm{~min}$ at $3,000 \times g$ and then lysed in four volumes of cold deionised water. Haemoglobin concentrations were assayed using a commercially available kit (Sigma, St Louis, MO, USA).

\section{Genotyping}

Genomic DNA was extracted from peripheral white cells using the commercially available QIAamp DNA Blood Mini Kit (QIAGEN, Hilden, Germany). PCR-based restriction fragment length polymorphism analysis was used to examine the single nucleotide polymorphisms of interest. Genotyping of Mn-SOD and catalase were carried out using standard methods, as described previously [16]. The genotype of DNA samples was identified blindly and controls (blank (without DNA template), positive and negative) were prepared and set up in association with each PCR operation. A random $10 \%$ of samples were regenotyped. Analyses were repeated at least once for any samples for which amplification or digestion failed.

\section{Measurement of specific antioxidant enzyme activities}

Superoxide dismutase

SOD activity in red blood cell lysate was determined from the rate of reduction of cytochrome $c$, as described previously [16], with one unit of SOD activity defined as the amount of SOD required to inhibit the rate of cytochrome $c$ reduction by $50 \%$. Xanthine oxidase (Sigma) was added at a concentration sufficient to induce a 0.020 change in absorbance per minute at $550 \mathrm{~nm}$. SOD activity is expressed in units per gram of haemoglobin.

\section{Catalase}

The quantification of catalase activity in the red blood cell lysate was based on the reaction with $\mathrm{H}_{2} \mathrm{O}_{2}$, as described previously [16]. In brief, the initial rate of disappearance of $\mathrm{H}_{2} \mathrm{O}_{2}(0-60 \mathrm{~s})$ was recorded spectrophotometrically at a wavelength of $240 \mathrm{~nm}$. One unit of catalase activity was defined as the rate constant of the first-order reaction. Catalase activity is expressed in milliunits per gram of haemoglobin.

\section{Statistical analysis}

Antioxidant enzyme activities were normally distributed (when tested using the Kolmogorov-Smirnov test) and are expressed as mean $\pm \mathrm{SD}$. Demographic data were compared between groups using Chi-squared analysis or an unpaired t-test, as appropriate. Differences in genotype and allele 
frequencies between patients and controls were tested using Chi-squared analyses in a $2 \times 2$ table or Fisher's exact test. Unconditional logistic regression models were applied to estimate the odds ratio and $95 \%$ confidence interval of genetic risk in COPD patients. As the patients and controls were well matched, no adjustment for age and smoking was necessary. Comparison of antioxidant enzyme activities between groups was carried out using an unpaired t-test. The influence of MnSOD and catalase gene polymorphisms on erythrocyte SOD and catalase activity among different genotype groups was tested by ANOVA. Post hoc multiple comparisons using Bonferroni correction were performed where appropriate. The Hardy-Weinberg equilibrium was estimated using the SNPAnalyzer program (Istech, Inc., Goyang-si, Gyeonggi-do, Korea) [17]. A p-value $<0.05$ was considered significant.

\section{RESULTS}

The characteristics of the COPD patients and healthy controls, matched for age and cumulative cigarette consumption, are shown in table 1 . Only 15 of the 165 COPD patients and four of the 165 healthy controls were female. COPD patients and controls did not differ in mean age and smoking history. There was, however, a significantly higher proportion of current smokers among healthy controls than among COPD patients. COPD patients had significantly lower lung function than healthy controls.

The Val allele of Mn-SOD (found in $89.6 \%$ of healthy controls and $86 \%$ of COPD patients) and the $C$ allele of the catalase gene (found in $96.6 \%$ of healthy controls and $94.8 \%$ of COPD patients) were present in the majority of subjects and did not differ between patients and controls (table 2). The prevalences of the Mn-SOD Val/Val, Val/Ala and Ala/Ala genotypes were $79.9,19.5$ and $0.6 \%$, respectively, in healthy controls, and did not differ from those found in COPD patients, 72.6, 26.8 and $0.6 \%$, respectively. The catalase $\mathrm{C} / \mathrm{C}, \mathrm{C} / \mathrm{T}$ and $\mathrm{T} / \mathrm{T}$ genotypes were present in 93.3, 6.7 and $0 \%$ of the controls, and 90.9, 7.9 and $1.2 \%$ of the patients, respectively. The frequency distributions of the Mn-SOD and catalase genotypes were in Hardy-Weinberg equilibrium in healthy controls and patients.

\begin{tabular}{lccc} 
TABLE 1 & Characteristics of study subjects & \\
& Control & COPD & p-value $^{\#}$ \\
\hline & 165 & 165 & \\
Subjects $\mathbf{n}$ & $161(97.6)$ & $150(90.9)$ & $<0.05$ \\
Males & $65.6 \pm 9.8$ & $66.8 \pm 8.2$ & 0.251 \\
Age yrs & & & \\
Smoking status & $80(48.5)$ & $44(26.7)$ & $<0.001$ \\
$\quad$ Current smoker & $85(51.5)$ & $121(73.3)$ & \\
$\quad$ Ex-smoker & $33.1 \pm 18.5$ & $33.6 \pm 18.1$ & 0.797 \\
Smoking history pack-yrs & $101.8 \pm 12.7$ & $34.5 \pm 12.9$ & $<0.001$ \\
FEV1 \% pred & $101.3 \pm 11.6$ & $63.7 \pm 18.3$ & $<0.001$ \\
FVC \% pred & $76.1 \pm 5.0$ & $41.2 \pm 10.9$ & $<0.001$ \\
FEV1/FVC \% & & & \\
\hline
\end{tabular}

Data are presented as mean \pm SD or $n(\%)$, unless otherwise stated. COPD: chronic obstructive pulmonary disease; FEV1: forced expiratory volume in one second; \% pred: \% predicted; FVC: forced vital capacity. ${ }^{*}$ : Chi-squared test or unpaired t-test, as appropriate.
The Ala/Ala genotype was combined with the Val/Ala genotype, and the $\mathrm{T} / \mathrm{T}$ genotype with $\mathrm{C} / \mathrm{T}$ genotype, in the analysis assessing risk of COPD, due to the low prevalence or complete absence of the Ala/Ala Mn-SOD polymorphism genotype and the $\mathrm{T} / \mathrm{T}$ catalase polymorphism genotype. There were also no significant differences in the genotype frequencies of the Mn-SOD and catalase polymorphisms between healthy controls and COPD patients classified according to severity on the basis of lung function (table 3).

Erythrocyte SOD activity did not differ between COPD patients and healthy controls, irrespective of genotype (table 4). Erythrocyte catalase activity was higher in COPD patients with the $\mathrm{C} / \mathrm{C}$ genotype, and with the combined $\mathrm{C} / \mathrm{T}$ and $\mathrm{T} / \mathrm{T}$ genotypes, than in healthy controls of similar genotypes. There were no significant differences in SOD and catalase activities between different genotypes among COPD patients and healthy controls.

No differences were found in erythrocyte SOD activity between healthy controls and COPD patients, irrespective of their smoking status (fig. 1a). Conversely, erythrocyte catalase activity was significantly higher in ex-smokers than in current smokers among healthy controls but not among COPD patients. However, COPD patients showed significantly higher erythrocyte catalase activity than healthy controls, irrespective of their smoking status (fig. 1b). No differences existed for erythrocyte SOD activity between patients of different COPD severity, classified according to FEV1 (\% pred), and healthy

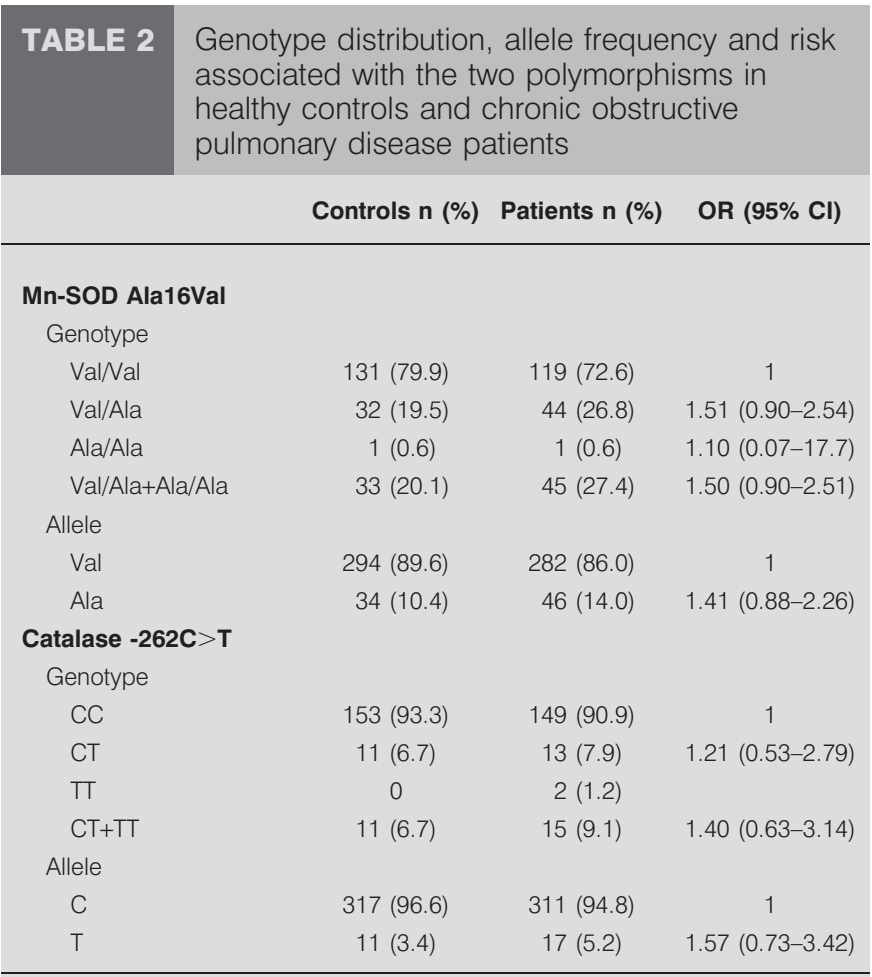

No results were obtained on genotyping for one patient. OR: odds ratio; $\mathrm{Cl}$ : confidence interval; Mn-SOD: manganese-superoxide dismutase; Ala16Val: substitution of alanine 16 with valine; $-262 \mathrm{C}>\mathrm{T}$ : cytosine to thymidine transition of nucleotide -262 . 
TABLE 3 Genotype frequency of manganese-superoxide dismutase (Mn-SOD) and catalase polymorphisms in healthy controls and chronic obstructive pulmonary disease patients classified according to severity on the basis of lung function

Controls $^{\#}$

Patients

p-value

FEV $1 \geqslant 50-79 \%$ pred $\quad$ FEV $1 \geqslant 30-49 \%$ pred $\quad$ FEV $1<30 \%$ pred

\begin{tabular}{|c|c|c|c|c|c|}
\hline $\mathrm{Val} / \mathrm{Nal}$ & 131 (79.9) & $16(66.7)$ & $53(71.6)$ & $50(75.8)$ & \multirow[t]{3}{*}{0.183} \\
\hline Val/Ala & $32(19.5)$ & $7(29.2)$ & $21(28.4)$ & $16(24.2)$ & \\
\hline Ala/Ala & $1(0.6)$ & $1(4.2)$ & $0(0)$ & $0(0)$ & \\
\hline Val/Ala+Ala/Ala & $33(20.1)$ & $8(33.3)$ & $21(28.4)$ & $16(24.2)$ & 0.349 \\
\hline \multicolumn{6}{|c|}{ Catalase $-262 C>T$} \\
\hline $\mathrm{C} / \mathrm{C}$ & $153(93.3)$ & $23(95.8)$ & 67 (90.5) & 59 (89.4) & 0.123 \\
\hline $\mathrm{C} / \mathrm{T}+\mathrm{T} / \mathrm{T}$ & $11(6.7)$ & $1(4.2)$ & $7(9.5)$ & 7 (10.6) & 0.640 \\
\hline
\end{tabular}

controls (fig. 2a). Although there were no significant differences in erythrocyte catalase activity between patients of different COPD severity, significantly higher erythrocyte catalase activity was found in patients of each severity of COPD compared with the healthy controls (fig. $2 b$ ).

\section{DISCUSSION}

Since only $\sim 25 \%$ of continuous smokers develop clinically significant airflow obstruction [6], it has been suggested that

\begin{tabular}{|c|c|c|c|c|c|}
\hline \multirow[t]{3}{*}{ TABLE 4} & \multicolumn{5}{|c|}{$\begin{array}{l}\text { Antioxidant enzyme activity in healthy controls } \\
\text { and chronic obstructive pulmonary disease } \\
\text { patients according to genotype }\end{array}$} \\
\hline & \multicolumn{2}{|c|}{ Controls } & \multicolumn{2}{|c|}{ Patients } & \multirow[t]{2}{*}{ p-value ${ }^{\#}$} \\
\hline & $\begin{array}{c}\text { Subjects } \\
n\end{array}$ & $\begin{array}{l}\text { Activity } \\
\mathrm{U} \cdot \mathrm{g}^{-1} \mathrm{Hb}\end{array}$ & $\begin{array}{c}\text { Subjects } \\
n\end{array}$ & $\begin{array}{l}\text { Activity } \\
\mathrm{U} \cdot \mathrm{g}^{-1} \mathrm{Hb}\end{array}$ & \\
\hline \multicolumn{6}{|c|}{ Mn-SOD Ala16Val } \\
\hline Total & 165 & $72.0 \pm 39.3$ & 161 & $70.0 \pm 34.8$ & 0.638 \\
\hline $\mathrm{Val} / \mathrm{Val}$ & 131 & $72.0 \pm 40.1$ & 116 & $71.0 \pm 34.0$ & 0.795 \\
\hline Val/Ala & 32 & $73.0 \pm 37.5$ & 43 & $69.0 \pm 37.5$ & 0.682 \\
\hline Ala/Ala & 1 & 48.0 & 1 & 44.0 & \\
\hline Val/Ala+Ala/Alc & 33 & $72.0 \pm 37.1$ & 44 & $69.0 \pm 37.3$ & 0.690 \\
\hline \multicolumn{6}{|c|}{ Catalase $-262 C>T$} \\
\hline Total & 165 & $0.034 \pm 0.016$ & 160 & $0.049 \pm 0.031$ & $<0.001$ \\
\hline $\mathrm{C} / \mathrm{C}$ & 153 & $0.034 \pm 0.016$ & 144 & $0.048 \pm 0.030$ & 0.001 \\
\hline $\mathrm{C} / \mathrm{T}$ & 11 & $0.032 \pm 0.019$ & 13 & $0.058 \pm 0.039$ & 0.056 \\
\hline$T / T$ & 0 & 0 & 2 & $0.077 \pm 0.005$ & \\
\hline $\mathrm{C} / \mathrm{T}+\mathrm{T} / \mathrm{T}$ & 11 & $0.032 \pm 0.019$ & 15 & $0.061 \pm 0.037$ & 0.028 \\
\hline
\end{tabular}

Data are presented as mean $\pm S D$, unless otherwise stated. No results were obtained on genotyping for one patient. $\mathrm{Hb}$ : haemoglobin; Mn-SOD: manganese-superoxide dismutase; Ala16Val: substitution of alanine 16 with valine; $-262 \mathrm{C}>\mathrm{T}$ : cytosine to thymidine transition of nucleotide -262 . \#: unpaired t-test. individual susceptibility is crucial in the pathogenesis of COPD. In the present study, no significant differences were found in the distribution of polymorphisms of Mn-SOD and catalase genes in COPD patients and healthy controls, nor were significant differences found in total SOD and catalase activity between different Mn-SOD and catalase genotypes. However, it was found that the frequencies of the Val allele of the MnSOD gene [18] and C allele of the catalase gene [13] were much higher than those reported for Caucasian populations.

There is now considerable evidence that oxidative stress arising from cigarette smoking plays an important role in the pathogenesis of COPD [1]. Free radicals and oxidants are present at high concentrations in cigarette smoke. In the lungs, cigarette smoke condensate, which is formed in the epithelial lining fluid, may continue to produce reactive oxygen species [2]. $\mathrm{H}_{2} \mathrm{O}_{2}$ was detected at 20-fold higher levels in breath condensates from COPD patients than from normal subjects [19]. The oxidative burden of cigarette smoke can be further enhanced in smokers' lungs by the release of oxygen radicals from inflammatory leukocytes found in the airway of smokers [20].

Enzymatic defence against activated oxygen species involves the cooperative action of several antioxidant enzymes. SOD is one of the key enzymes that detoxifies $\mathrm{O}_{2}^{--}$and generates $\mathrm{H}_{2} \mathrm{O}_{2}$ and which, in turn, is detoxified by GPx and catalase [4]. The results of studies of antioxidant enzyme activities in smokers have been controversial. The activities of SOD and catalase have been reported to be increased in human alveolar macrophages [21]. However, some studies observed that the induction of Mn-SOD was transient and that antioxidant enzymes may even be downregulated during severe or chronic oxidant exposure in animal models [21, 22]. The failure to demonstrate significant differences in erythrocyte SOD activity between current smokers and ex-smokers in the present study, and between life-long nonsmokers and ever smokers in a previous study [16], are consistent with another published report [23]. The present findings suggest that COPD patients do not show altered erythrocyte SOD activity, contrary to the 

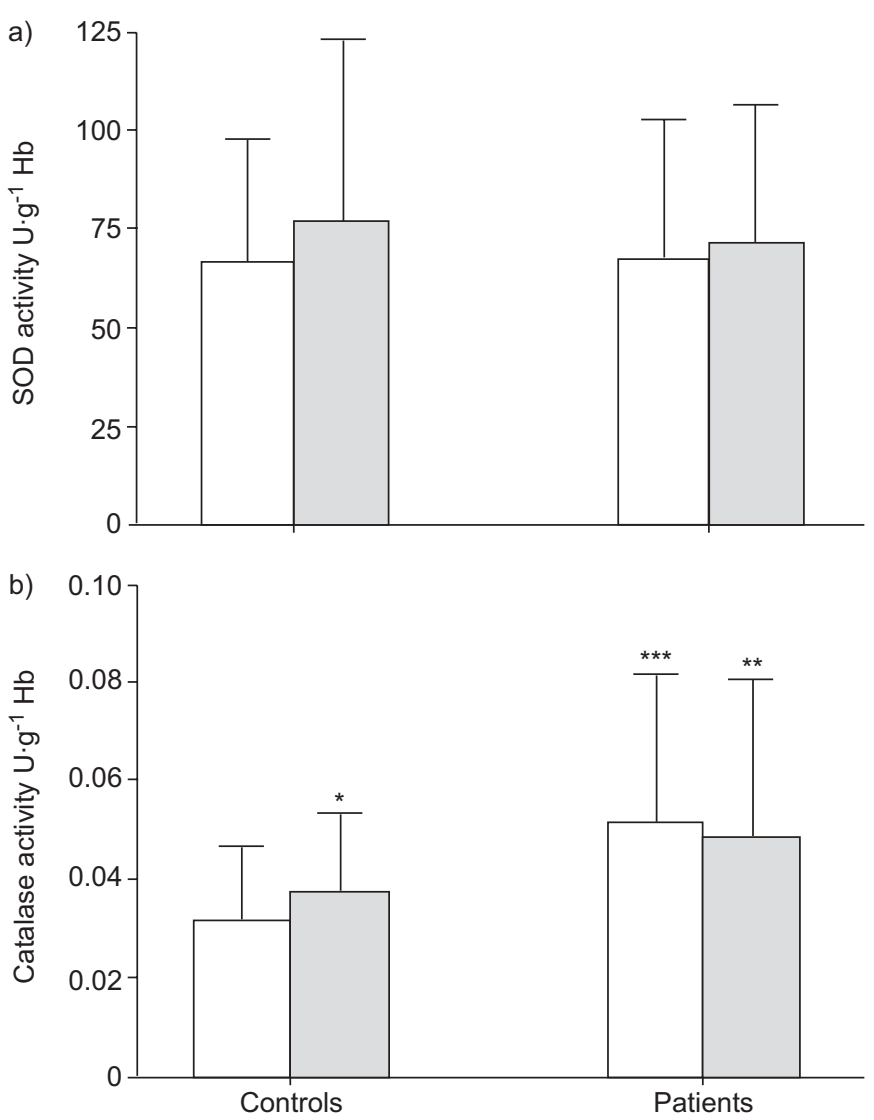

FIGURE 1. Erythrocyte antioxidant enzyme activity in current $(\square)$ and exsmokers ( $\square$ ) among healthy controls ( $\mathrm{n}=80$ and 85 , respectively) and chronic obstructive pulmonary disease patients ( $n=44$ and 117 , respectively): a) superoxide dismutase (SOD); and b) catalase. Data are presented as mean $\pm \mathrm{SD}$. $\mathrm{Hb}$ : haemoglobin. *: $p<0.05$; and ${ }^{*}: p<0.01$ versus healthy control current smokers; $* * *: p<0.001$ versus healthy control ex-smokers.

findings of previous studies [23, 24] but in agreement with more recent reports $[25,26]$.

It was found that erythrocyte catalase activity was increased in COPD patients compared with healthy controls, irrespective of smoking habits. This may indicate a compensatory-adaptive response to excessive accumulation of oxygen free radicals due to cigarette smoking in COPD patients, as the $\mathrm{H}_{2} \mathrm{O}_{2}$ produced may be scavenged by the increased catalase activity. Among the present controls, catalase activity was significantly higher in ex-smokers than in current smokers. Although healthy smoking controls may also be subjected to oxidative stress, they do not have COPD and might not exhibit the compensatory increase in erythrocyte catalase activity, which is supported by previous reports $[27,28]$.

In the present study, the functional polymorphisms of the MnSOD and catalase genes studied may not be responsible for the changes in erythrocyte SOD and catalase activity. Mn-SOD activity was not specifically measured since Mn-SOD activity accounts for $\sim 90 \%$ of total SOD activity. The Ala ${ }^{16}$ allele of the mitochondrial targeting sequence of the Mn-SOD gene has an $\alpha$-helical structure, whereas the $\mathrm{Val}^{16}$ allele does not [8]. As an amphiphilic helical structure is an essential requirement for
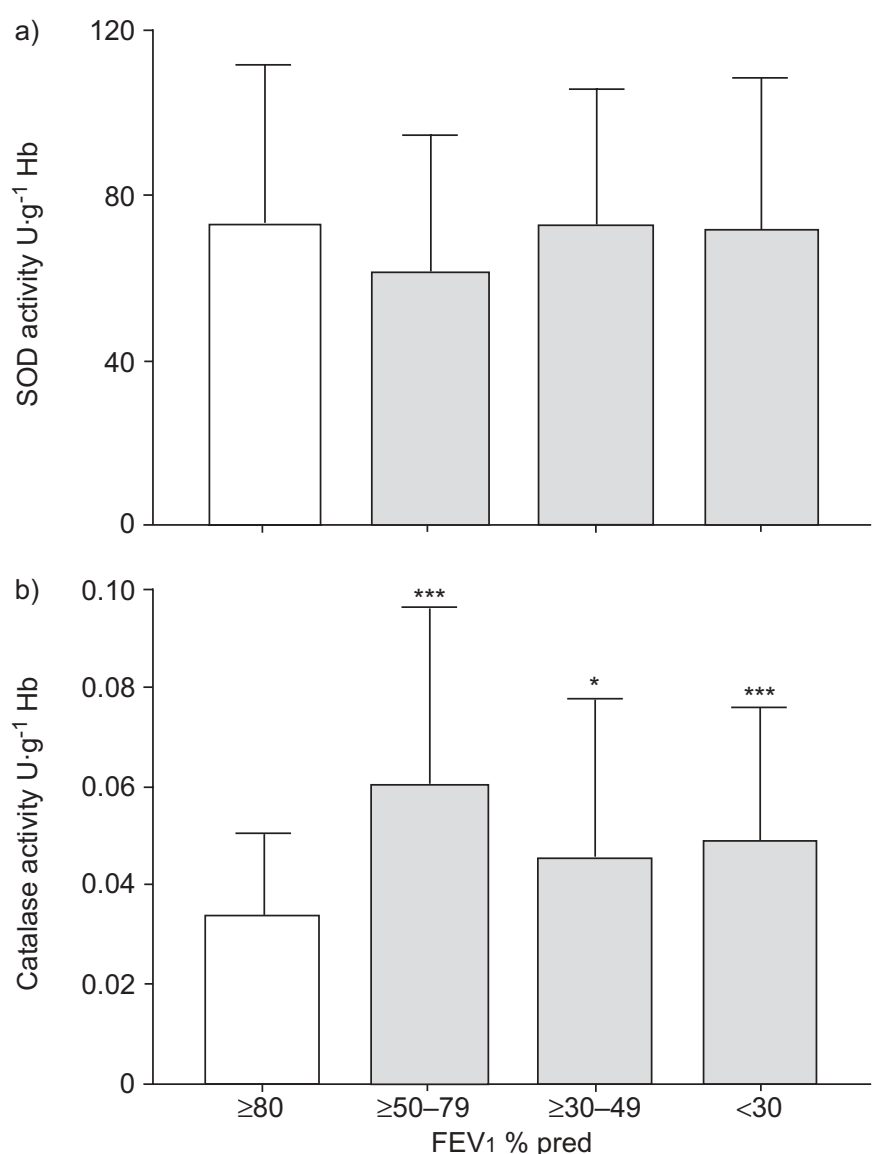

FIGURE 2. Erythrocyte antioxidant enzyme activity in chronic obstructive pulmonary disease patients $(\square)$ and healthy controls (forced expiratory volume in one second ( $\left.F E V_{1}\right) \geqslant 80 \%$ predicted; $\square ; n=165$ ) by severity of airflow obstruction ( $n=23$ for $\geqslant 50-79 \%$ pred; $n=71$ for $\geqslant 30-49 \%$ pred; $n=67$ for $<30 \%$ pred): a) superoxide dismutase (SOD); and b) catalase. Data are presented as mean $\pm \mathrm{SD}$. $\mathrm{Hb}$ : haemoglobin. *: $\mathrm{p}<0.05$; ***: $\mathrm{p}<0.001$ versus $\mathrm{FEV} 1 \geqslant 80 \%$ pred.

efficient mitochondrial transport, the Mn-SOD precursor protein with the $\mathrm{Ala}^{16}$-type signal peptide may be more easily transported into mitochondria than the precursor with the $\mathrm{Val}^{16}$-type signal peptide. Accordingly, the activity of Mn-SOD tetramers in the mitochondrial matrix was $\sim 40 \%$ higher after mitochondrial import of the $\mathrm{Ala}^{16} \mathrm{Mn}-\mathrm{SOD}$ precursor than after import of the $\mathrm{Val}^{16} \mathrm{Mn}-\mathrm{SOD}$ precursor [29]. The functional polymorphism of the SOD3 gene, $+760 \mathrm{C}>\mathrm{G}$ (substitution of arginine 213 with glycine), has been reported to confer a degree of resistance to the development of COPD in smokers [10]. Thus further studies are needed in order to detect functional polymorphisms of the two other isoforms of SOD in the present population.

The $-262 \mathrm{C}>\mathrm{T}$ polymorphism of the promoter region of the human catalase gene has been shown to influence transcription factor binding and correlate with blood catalase levels [13]. Unfortunately, in the Chinese population, the homozygous T/ $\mathrm{T}$ genotype is rare, occurring in none of the present healthy controls and two out of the 164 COPD patients. It is impossible to adequately assess the functional activity of those with the $\mathrm{T} / \mathrm{T}$ genotype. It is notable that increased catalase activity was 
found in COPD patients compared with the healthy controls, irrespective of genotype. One previous report found significant racial differences in free radical-scavenging enzyme activity in children [30]. Exclusively Chinese subjects from the same area, i.e. Hong Kong or the Guangdong province of Southern China, were studied in order to minimise the internal heterogeneity of the population.

Although there was a failure to provide any evidence of the functional polymorphic Mn-SOD and catalase gene alleles of interest conferring genetic COPD susceptibility, the potential impact of enhanced catalase activity in COPD patients in the present cohort remains unclear. It is important to remember that catalase is not the only enzyme responsible for the detoxification of $\mathrm{H}_{2} \mathrm{O}_{2}$. GPx is also capable of eliminating $\mathrm{H}_{2} \mathrm{O}_{2}$. Moreover, most antioxidant systems are interrelated and interconnected.

The strengths of the present study are that the COPD patients and healthy controls were well matched according to age and smoking history, and that the functional activity of SOD and catalase were measured in addition to determining the different Mn-SOD and catalase genotypes. However, it has limitations. First, the patients were not properly matched to controls by sex or smoking status (ex-smokers/current smokers). The numbers of males and females were not balanced, because the majority of COPD patients and chronic smokers in Hong Kong are male. Although a large pool of COPD patients was recruited from five hospitals in different parts of Hong Kong, the sample size was still relatively small due to the limited numbers of healthy smoking controls with normal lung function in the general population study. Secondly, the dietary intake of antioxidants, which is mainly responsible for SOD and catalase activity, was not quantified. Thirdly, measurements of antioxidant enzyme activity were carried out only on erythrocytes, which might not reflect local levels in the lungs. In addition, measurements of SOD and catalase activity were taken at one random point in time, which ignores any variability in these parameters over time. Fourthly, as the present study is a cross-sectional study, it is not possible to determine whether lung function impairment or respiratory symptoms are the result or the cause of the higher catalase activity. The present study should be considered preliminary and further studies should be performed on a larger population.

In conclusion, the findings of the present study do not support the notion that functional polymorphisms of these two key antioxidant enzymes, manganese-superoxide dismutase and catalase, confer genetic susceptibility to chronic obstructive pulmonary disease in the Hong Kong Chinese population. The increase in erythrocyte catalase activity of chronic obstructive pulmonary disease patients may be indicative of a dysfunction of the oxidant/antioxidant defence system. Other, as yet unidentified, antioxidative processes may be more relevant as determinants of the development of chronic obstructive pulmonary disease in the Chinese population.

\section{ACKNOWLEDGEMENTS}

The authors would like to thank all of the study subjects for their participation, A. Dybuncio (University of British Columbia, Vancouver, BC, Canada) for conducting the statistical analysis of the data, and C. Ho, K. Chow and A.
Lai (The University of Hong Kong, Hong Kong SAR, China) for assisting in data collection.

\section{REFERENCES}

1 Sethi JM, Rochester CL. Smoking and chronic obstructive pulmonary disease. Clin Chest Med 2000; 21, 67-86: viii.

2 Pryor WA, Stone K. Oxidants in cigarette smoke. Radicals, hydrogen peroxide, peroxynitrate, and peroxynitrite. Ann NY Acad Sci 1993; 686: 12-27.

3 Rahman I, MacNee W. Role of oxidants/antioxidants in smoking-induced lung diseases. Free Radic Biol Med 1996; 21: 669-681.

4 Reiter RJ. Oxidative processes and antioxidative defense mechanisms in the aging brain. FASEB J 1995; 9: 526-533.

5 Matés JM, Pérez-Gómez C, Núñez de Castro I. Antioxidant enzymes and human diseases. Clin Biochem 1999; 32: 595-603.

6 Løkke A, Lange P, Scharling H, Fabricius P, Vestbo J. Developing COPD: a 25 year follow up study of the general population. Thorax 2006; 61: 935-939.

7 Wan XS, Devalaraja MN, St Clair DK. Molecular structure and organization of the human manganese dismutase gene. DNA Cell Biol 1994; 13: 1127-1136.

8 Shimoda-Matsubayashi S, Matsumine H, Kobayashi T, Nakagawa-Hattori Y, Shimizu Y, Mizuno Y. Structural dimorphism in the mitochondrial targeting sequence in the human manganese superoxide dismutase gene. A predictive evidence for conformational change to influence mitochondrial transport and a study of allelic association in Parkinson's disease. Biochem Biophys Res Commun 1996; 226: 561-565.

9 Wang LI, Miller DP, Sai Y, et al. Manganese superoxide dismutase alanine-to-valine polymorphism at codon 16 and lung cancer risk. J Natl Cancer Inst 2001; 93: 1818-1821.

10 Young RP, Hopkins R, Black PN, et al. Functional variants of antioxidant genes in smokers with COPD and in those with normal lung function. Thorax 2006; 61: 394-399.

11 Quan F, Korneluk RG, Tropak MB, Gravel RA. Isolation and characterization of the human catalase gene. Nucleic Acids Res 1986; 14: 5321-5335.

12 Hirono A, Sasaya-Hamada F, Kanno H, Fujii H, Yoshida T, Miwa S. A novel human catalase mutation (358 T-->del) causing Japanese-type acatalasemia. Blood Cells Mol Dis 1995; 21: 232-234.

13 Forsberg L, Lyrenäs L, de Faire U, Morgenstern R. A common functional C-T substitution polymorphism in the promoter region of the human catalase gene influences transcription factor binding, reporter gene transcription and is correlated to blood catalase levels. Free Radic Biol Med 2001; 30: 500-505.

14 Global Initiative for Chronic Obstructive Lung Disease. Global Strategy for the Diagnosis, Management, and Prevention of Chronic Obstructive Pulmonary Disease. Workshop Report 2006 Update. www.goldcopd.org/ Guidelineitem.asp? $11=2 \& 12=1 \&$ intId $=989$ Date last updated: January 22, 2007. Date last accessed: January 23, 2007.

15 Ip MS, Ko FW, Lau AC, et al. Updated spirometric reference values for adult Chinese in Hong Kong and implications on clinical utilization. Chest 2006; 129: 384-392. 
16 Mak JCW, Leung HCM, Ho SP, et al. Polymorphisms of superoxide dismutase and catalase genes and functional activity levels in Chinese patients with asthma. Clin Exp Allergy 2006; 36: 440-447.

17 Istech, SNPAnalyzer. http://snp.istech.info/snp/ Date last updated: August 8, 2005. Date last accessed: December 20, 2006.

18 Ambrosone CB, Freudenheim JL, Thompson PA, et al. Manganese superoxide dismutase (MnSOD) genetic polymorphisms, dietary antioxidants and risk of breast cancer. Cancer Res 1999; 59: 602-606.

19 Dekhuijzen PN, Aben KK, Dekker I, et al. Increased exhalation of hydrogen peroxide in patients with stable and unstable chronic obstructive pulmonary disease. Am J Respir Crit Care Med 1996; 154: 813-816.

20 Hunninghake GW, Crystal RG. Cigarette smoking and lung destruction. Accumulation of neutrophils in the lungs of cigarette smokers. Am Rev Respir Dis 1983; 128: 833-838.

21 McCusker K, Hoidal J. Selective increase of antioxidant enzyme activity in the alveolar macrophages from cigarette smokers and smoke-exposed hamsters. Am Rev Respir Dis 1990; 141: 678-682.

22 Gilks CB, Price K, Wright JL, Churg A. Antioxidant genes expression in rat lung after exposure to cigarette smoke. Am J Pathol 1998; 152: 269-278.

23 Kurys E, Kurys P, Kuzniar A, Kieszko R. Analysis of antioxidant enzyme activity and magnesium level in chronic obstructive pulmonary disease (COPD). Ann Univ Mariae Curie Sklodowska [Med] 2001; 56: 261-266.

24 Matskevich GN, Korotkina RN, Devlikanova ASh, Vishnevski AA, Karelin AA, [The study of the antioxidant enzymes in erythrocytes in lung diseases]. Patol Fiziol Eksp Ter 2003; 2: 23-25.

25 Hanta I, Kocabas A, Canacankatan N, Kuleci S, Seydaoglu G. Oxidant-antioxidant balance in patients with COPD. Lung 2006; 184: 51-55.

26 Kluchová Z, Petrásová D, Joppa P, Dorková Z, Tkácová R. The association between oxidative stress and obstructive lung impairment in patients with COPD. Physiol Res 2007; 56: 51-56.

27 Durak I, Yalçin S, Burak Cimen MY, Büyükkoçak S, Kaçmaz M, Oztürk HS. Effects of smoking on plasma and erythrocyte antioxidant defense systems. J Toxicol Environ Health A 1999; 56: 373-378.

28 Orhan H, Evelo CTA, Sahin G. Erythrocyte antioxidant defense response against cigarette smoking in humans the glutathione S-transferase vulnerability. J Biochem Mol Toxicol 2005; 19: 226-233.

29 Sutton A, Imbert A, Igoudjil A, et al. The manganese superoxide dismutase Ala16Val dimorphism modulates both mitochondrial import and mRNA stability. Pharmacogenet Genomics 2005; 15: 311-319.

30 Glauser TA, Titanic-Schefft M, Pippenger CE. Racial differences in free radical scavenging enzyme activity in children. J Child Neurol 1999; 14: 382-387. 